\title{
Association of Socioeconomic Status with Preeclampsia in Pakistani Females
}

\author{
Saima Ejaz ${ }^{1}$, Reem Yaqoub $^{2}$, Reem AlKahtani ${ }^{3}$, Anila Khalique ${ }^{4}$, Maryam Azam $^{1}$, Nosheen Mahmood ${ }^{1}$, \\ Nada Saleh ${ }^{3}$ \\ ${ }^{1}$ Department of Basic Medical Sciences, College of medicine, King Saud bin Abdul Aziz University of \\ health Sciences \\ ${ }^{2}$ College of medicine, King Saud bin Abdul Aziz University of health Sciences \\ ${ }^{3}$ Department of Basic Medical Sciences, College of Medicine, King Saud bin Abdul Aziz University of \\ health Sciences \\ ${ }^{4}$ Department of Diabetes and Endocrinology, Sharjah University
}

Received: November 15, 2021 Accepted: December 17, 2021 DOI: $10.46568 /$ bios.v2i 2.54

\begin{abstract}
:
Introduction: To identify whether there is an association between maternal socioeconomic status as in living style, and preeclampsia in women from Pakistan, and if so, to what extent it increases the risk of developing preeclampsia.

Methods: This is a case-control study, consisting of 74 normal pregnant and 76 already diagnosed preeclamptic Pakistani females, recruited from various hospitals in Karachi. Their socioeconomic status was assessed through the standard of living index (SLI) using the National Family Health Surveys (NFHS) criteria, which considers different living facilities as an indicator of socioeconomic status. Odds ratios of preeclampsia were calculated for low, middle and high socioeconomic status and other maternal anthropometric parameters.

Results: Based on their groups, it appeared that the highest percentage of preeclamptic females $(n=65 ; 43.3 \%)$ and the lowest of control patients $(\mathrm{n}=14 ; 9.3 \%)$ lie in lower socioeconomic groups and the results were highly significantly different. Study observed that having lower socioeconomic status $(\mathrm{P}<0.001)$ significantly increase risk of having preeclampsia by $9 \%$ and middle socioeconomic status has no role in prevalence of preeclampsia shown by 0.0 odds ratio. In addition, odds ratio of age and PreBMI for the preeclamptic females were found as $1.37(\mathrm{P}<0.001)$ and $1.55(\mathrm{P}<0.001)$ respectively, which shows that each year increase in age, increases risk of preeclampsia by 1.37 times and 1.55 times with each increased in BMI.

Conclusion: Living facilities are indications of socioeconomic status and $c$ strong risk factors of preeclampsia
\end{abstract}

Keywords: Preeclampsia, Socioeconomic status, Standard of living index

*Correspondence: Saima Ejaz, Lecturer, Department of Basic Medical Sciences, College of medicine, King Saud bin Abdul Aziz University of health Sciences, Riyadh, Saudi Arabia Tel: 00966504944219

Email: saimaejaz84@outlook.com

\section{INTRODUCTION:}

Preeclampsia is the most prevalent devastating disorder of pregnancy that causes about $5 \%$ of all pregnancy cases worldwide [1]. Previously, it was characterized by having high blood pressure (Systolic: $>140 \mathrm{~mm}$ of $\mathrm{Hg}$ and diastolic: $>90 \mathrm{~mm}$ of $\mathrm{Hg}$ ) with high proteinuria after 20 weeks of pregnancy. Recently, the criteria have been revised and according to the American College of Obstetricians and Gynaecologist guidelines [2], diagnosis of preeclampsia no longer requires proteinuria but can be associated with other manifestations of kidney, lungs, liver, visual disturbances, or other signs of brain damage. Preeclampsia can lead to fetal and maternal morbidity and mortality if it developed into eclampsia, which is serious fatal complication characterized by seizures [3]. Preeclamptic maternal risk factors consist of youthful mothers, first 
pregnancy, previous history of preeclampsia, early-onset of disease, pre-existing medical conditions such as lupus erythematosus, antiphospholipid syndrome, previously diagnosed diabetes or hypertension [4].

The precise pathophysiology of preeclampsia is still poorly implicit, however, there are multiple theories that have been proposed for the mechanism and abnormalities found in this condition [5], involving both fetal/placental and maternal factors. Among all theories in preeclampsia, one is abnormal placentation [6] caused by reduced perfusion to the placenta. During early pregnancy, trophoblastic cells invade the uterus and remodel the small, high resistance spiral arteries into large blood vessels with high capacitance [7]. This process initiates after completion of the first trimester, usually by $18-20$ weeks of gestation. High resistant spiral arteries remain persistently due to failure in this process, in addition to the obstruction in placental perfusion resulting in "relative hypoxemia". This will eventually increase circulating soluble fms-like tyrosine kinase-1(sFlt1), while decreasing the placental growth factor (PGF) and vascular endothelial growth factor (VEGF) signalling into the mother's blood leading to dysfunction of maternal endothelial cells [8]. The dysfunction in maternal endothelial cells exhibits many signs and symptoms due to maternal vasoconstriction and multi-organ damage. As the pregnancy progresses, sign and symptoms become more pronounced due to the increasing demand of feto-placental unit. Late modifications in the placental tissue corresponds with ischemia found in atherosis, fibroid necrosis, sclerosis of the arterioles, thrombosis, and infarction [9].

The identified risk factors help control the severity of the disease. Risk of preeclampsia increases 7 folds with having a previous history of this condition. It is believed that genetic factors also play a strong role in the aetiology of the disease [10]. Literature shows that those women, who had a positive family history of preeclampsia, have a higher risk of getting it than those without a family history or are nulliparous (first pregnancy). Obesity, hypertension, diabetes, African American background, multiple gestations, and assisted reproduction further increase the chances of having preeclampsia are some of the known risk factors [11]. Signs of exaggerated inflammation and/or infection have also been observed in preeclamptic females due to the debris of the outer layer of trophoblast. Furthermore, many studies demonstrated a relationship between preeclampsia and maternal infection such as periodontal diseases and urinary tract infection, which have shown an increasing risk of preeclampsia in pregnant females [12]. Sign and symptoms include visual disturbances, thrombocytopenia, pain in the epigastric region, and decreased liver function which are caused from microangiopathy to target organs such as: the brain, liver, placenta, and kidney [13]. Many complications can occur due to this disease for example: Pulmonary edema, cerebral hemorrhage, hepatic or renal failure, and even death. Based on the severity of the disease, preeclampsia is further classified into many different categories [14]. After 20 weeks of gestation, new onset hypertension (systolic $=140 \mathrm{~mm}$ of $\mathrm{Hg}$ and diastolic $=90 \mathrm{~mm}$ of $\mathrm{Hg}$ ) with proteinuria $(+1$ on dipstick or more than $300 \mathrm{mg} / \mathrm{dl}$ in 24 hours urinary excretion) without other symptoms or abnormalities is termed as mild preeclampsia. Patients diagnosed with end-organ dysfunction with systolic blood pressure (SBP) of more than $160 \mathrm{mmHg}$ or diastolic (DBP) more than $110 \mathrm{mmHg}$ are termed as severe Preeclampsia. Preeclampsia causes reduction in the blood supply to the placenta, which results in the deficiency of amniotic fluid (oligohydramnios) and intrauterine growth restriction (IUGR) of the fetus [15]. Perinatal mortality is mainly linked to intrauterine asphyxia, placental abruption, and premature delivery. Intraventricular hemorrhage, respiratory distress syndrome, and necrotizing enterocolitis are more common neonatal preeclamptic complications, as compared to normotensive pregnant females [16]. To prevent placental hypo perfusion and maternal complications, it is always advised to go for preterm delivery. Despite broad research, the trigger for abnormal placental development and pathophysiology of preeclampsia is not fully understood. No proper prevention has been discovered, and treatment is aimed to cure of the symptoms only. 
Low socioeconomic status contributes to the incidence of preeclampsia as it is linked to multiple conditions such as obesity, hypertension, metabolic syndrome, and cardiovascular diseases. Having poor income commonly affects medical care access and is associated with worse obstetric outcomes. In addition, being obese while pregnant, which is usually comorbid with hypertension and diabetes, provides a higher predisposition to the disease. Also, low socioeconomic status usually correlates with lack of education or knowledge about conditions affecting pregnancies which makes knowing the side effects and dealing with the symptoms delayed. This delay along with poor medical services will worsen the outcomes and decrease the risk of treatment success. Previous studies related to this topic weren't successful in finding a relationship between these two variables, as some showed negative correlations while others found no association whatsoever. Therefore, this study was first of its kind that is conducted on Pakistani pregnant females aimed to determine the association of socioeconomic status with the occurrence of preeclampsia in Pakistani females.

\section{METHODS:}

A retrospective case-control study was carried out on already diagnosed preeclamptic Pakistani females to determine the association of socioeconomic status and prevalence of preeclampsia. The study subjects were brought about from different hospitals in Karachi with an age range of 20-40 years old and divided into normal and preeclamptic groups. Using the Rao soft online calculator with a $95 \%$ confidence interval and a 6.3 margin of error, a total of 150 women were recruited. Pregnant females with blood pressures of SBP $<140 \mathrm{~mm} \mathrm{Hg}$ and DBP of $<90$ were included in the control group, who weren't receiving hormone replacement therapy nor cardiovascular treatments during the time of the study. In order to be diagnosed with preeclampsia, the criteria was to have hypertension $(\geq 140 / 90 \mathrm{mmHg})$ after 20 weeks of pregnancy with proteinuria ( $\geq 1+$ on dipstick), or without proteinuria but exhibiting one of these signs: thrombocytopenia, disturbed liver function, renal dysfunction, edema in lungs, visual or cerebral.

Subjects who presented with a medical history of hepatic or kidney diseases, diabetes, hypercholesterolemia, and heart failure were excluded from the study. The study was conducted in accordance with the guidelines proposed in the World Medical Association Declaration of Helsinki and was approved by institutional review board of Dow university of health sciences. The chosen subjects were given a written consent prior to the beginning of the study. History was taken through a detailed survey following a physical examination ruling out other diseases. However, the weight before pregnancy was obtained verbally from the first antenatal visit. Furthermore, all the study's advantages and risks were provided verbally to the participants.

\section{STATISTICAL ANALYSIS:}

Statistical Package of Social Sciences version 26.0 for Windows (SPSS Inc, Chicago, Illinois, USA) was used to analyze all data. To observe the significant differences between the socioeconomic status of preeclamptic and normal pregnant females, Chi square was used and for continuous variables independent t-test was applied. To observe the relation of socioeconomic status and risk of preeclampsia, odds ratios were calculated by multiple logistic regression at $95 \%$ confidence intervals $(95 \% \mathrm{CI})$.

\section{DETERMINATION OF SOCIOECONOMIC STATUS:}

Socioeconomic status was assessed through the standard of living index (SLI) using the National Family Health Surveys (NFHS) criteria, which could be used for both urban and rural population including 23 questions related to six main variables: water source, Type of residence, electricity source, cooking facilities, toilet accommodations, and property of items. The SLI has been commonly utilized by the NFHS and World Bank to define the socioeconomic status of 
populations [17]. We used the same tool to measure the economic status of our subjects. Socioeconomic status was considered Low-if total score was $<=9$; Medium - if total score was $>$ 9 to $<=19$; and High- if the score $>19$.

\section{RESULTS:}

Of the 150 females, average age of normal pregnant females was $24.41 \pm 3.29$, and 32.31 \pm 5.4 of preeclamptic females. A pre-pregnancy body mass index was compared between the control and preeclamptic female and found to be significantly greater $(\mathrm{p}=0.005)$ in preeclamptic females $(30.44 \pm 5.3)$ as compared to control group $(23.61 \pm 2.9)$. Mean systolic and diastolic blood pressures (DBP and SBP) recordings were also significantly different between the control and preeclamptic group with mean values of $127.73 \pm 4.7 ; 89.75 \pm 2.66$ and $158.87 \pm 16.3$; $101.92 \pm 11.05$ respectively (Table I).

The observed study samples showed that the majority of women were in their last trimester. As mean pregnancy weeks in control were found with $33.97+1.90$ and $35.4+3.84$ in the preeclamptic group.

Table I:

Clinical Characteristics of Control and Preeclamptic females

\begin{tabular}{|c|c|c|c|}
\hline Characteristics & $\begin{array}{r}\text { Control } \\
(n=74)\end{array}$ & $\begin{array}{l}\text { Preeclamptic } \\
\text { females } \\
\quad(n=76)\end{array}$ & P-value \\
\hline Age (Years) & $24.41 \pm 3.29$ & $32.31 \pm 5.4$ & $0.02 *$ \\
\hline PreBMI $\left(\mathrm{kg} / \mathrm{m}^{2)}\right.$ & $23.61 \pm 2.93$ & $30.44 \pm 5.3$ & $0.005 * *$ \\
\hline Systolic blood pressure ( $\mathrm{mm}$ of $\mathrm{Hg}$ ) & $127.73 \pm 4.7$ & $158.87 \pm 16.3$ & $<0.001 * * *$ \\
\hline Diastolic blood pressure ( $\mathrm{mm}$ of $\mathrm{Hg}$ ) & $89.75 \pm 2.66$ & $101.92 \pm 11.05$ & $<0.001 * * *$ \\
\hline Gestational age (weeks) & $33.97 \pm 1.90$ & $35.4 \pm 3.84$ & $0.04 *$ \\
\hline $\begin{array}{l}\text { Education } \\
\text { Illiterate } \\
\text { Matric } \\
\text { Inter } \\
\text { Graduate } \\
\text { Post-graduate }\end{array}$ & $\begin{array}{ll}23 & (15.3) \\
18 & (12) \\
14 & (9) \\
12 & (8) \\
7 & (4.7) \\
\end{array}$ & $\begin{array}{ll}31 & (20.7) \\
26 & (17.3) \\
15 & (10) \\
4 & (2.7) \\
0 & (0.0) \\
\end{array}$ & $0.009 * *$ \\
\hline
\end{tabular}

*** Significant at $\mathrm{P}<0.001,{ }^{*}$ Significant at $\mathrm{P}<0.01, \mathrm{NS}=$ Non-Significant

Patients' parity status was also noted during the study, and it was observed that most of the women $(91.7 \%)$ were multipara and only $8.3 \%$ were pri-mipara. A significant association $(\mathrm{p}=$ 0.005 ) was noticed in the family history of preeclamptic females as compared to control. Among all subjects, it was noted that $65.8 \%$ of preeclamptic cases had a positive family history, and majority of them were illiterate $(31 ; 20.7 \%)$.

Evaluation of socioeconomic status revealed that significant number $(\mathrm{P}<0.001)$ of preeclamptic females $43.3 \%(n=65)$ belonged to lower socioeconomic group; about $7.3 \%(n=11)$ belonged to the middle class, whereas none of the patient $(n=0)$ was of upper class category. Whereas most of the normal pregnant females $(n=35 ; 23.3 \%)$ lie in upper socioeconomic groups, and very few with lower socioeconomic status $(n=14 ; 9.3 \%)$, as illustrated in Table II. 
Biosight 2021; 02(02): 50-57

\begin{tabular}{|l|c|c|c|c|}
\hline & Upper n (\%) & Middle n (\%) & Lower n (\%) & P value \\
\cline { 1 - 4 } $\begin{array}{l}\text { Normal pregnant } \\
\text { females }\end{array}$ & $35(23.3)$ & $25(16.7)$ & $14(9.3)$ & \multirow{2}{*}{$<0.001 * * *$} \\
\cline { 1 - 4 } Preeclamptic females & $0(0)$ & $11(7.3)$ & $65(43.3)$ & \\
\cline { 1 - 4 } Total & $35(23.3)$ & $36(24)$ & $79(52.7)$ & \\
\hline
\end{tabular}

$* * *$ Significant at $\mathrm{P}<0.001$

Odds ratio (OR) were calculated to observe the risk of having preeclampsia with different demographic characteristics. Study observed that having lower socioeconomic status $(\mathrm{P}<0.001)$ significantly increase risk of developing preeclampsia up to $9 \%$ and middle socioeconomic status has no role in prevalence of preeclampsia showed by 0.0 odds ratio. In addition, OR of age and PreBMI for the preeclamptic females were found as $1.37(\mathrm{P}<0.001)$ and $1.55(\mathrm{P}<0.001)$ respectively, which shows that each 1 year increase in age increases risk of preeclampsia by 1.37 times and 1.55 times with each increased in BMI. Further, multi-parity and positive family history were also found as significant risk factors with odds ratio of $1.697(\mathrm{P}=0.003)$ and 3.52 $(\mathrm{P}=0.001)$, shown in Table III.

Table III:

Binary logistic regression analysis of the risk factors for Preeclampsia

\begin{tabular}{|l|c|c|c|}
\hline Risk factors of preeclampsia & P values & OR & 95\% CI \\
\hline Age & $<0.001 * * *$ & 1.369 & $1.237-1.516$ \\
\hline BMI & $<0.001 * * *$ & 1.505 & $1.319-1.717$ \\
\hline Parity & $0.003 * *$ & 1.697 & $1.200-2.398$ \\
\hline Family history & $0.001 * *$ & 3.523 & $1.633-7.600$ \\
\hline $\begin{array}{l}\text { Socioeconomic Status } \\
\text { Low } \\
\text { Middle }\end{array}$ & $<0.001 * * *$ & 0.095 & $0.038-0.237$ \\
& $0.99^{\mathrm{NS}}$ & 000 & 0.000 \\
\hline
\end{tabular}

*** Significant at $\mathrm{P}<0.001, * *$ Significant at $\mathrm{P}<0.01, \mathrm{NS}=$ Non-Significant

OR: odds ratio; CI: confidence interval; SNP: single-nucleotide polymorphism.

\section{DISCUSSION:}

The Present study showed a significant difference in pre-pregnancy body mass index (PreBMI) between control and preeclamptic patients, which is in accordance with the results of Mrema et al, who established a decisive link higher preBMI and the risk of preeclampsia [18]. Similar findings were presented by Savitry and her colleagues in PreBMI of hypertensive and preeclamptic patients who has shown that higher pre-pregnancy BMI is linked substantially with higher SBP $(\mathrm{p}<0.01)$ and DBP $(\mathrm{p}<0.01)$ in adjusted analysis [19]. Therefore, high BMI leads to higher Blood pressure which will consequently increase the risk of preeclampsia. Which also why obesity was noted among all $75 \%$ of preeclamptic and as one of the reviews, Jeyabalan mentioned that obesity contributes to cardiovascular disease and preeclampsia [20]. In obese individuals, multiple inflammatory mediators, like tumor necrosis factor alpha, $\mathrm{C}$ reactive proteins, interleukin 6 are produced by adipose tissues [21]. All of which contribute to the worsening of cardiovascular outcomes and morbidity. These inflammatory markers were found to be elevated in early pregnancy and develop later in preeclampsia possibly from adipose tissue. TNF alpha itself causes an increase in insulin resistance, activates endothelial cells, and generates oxidative stress. Therefore, when an obese woman gets pregnant those inflammatory mediators increase significantly increasing the incidence of preeclampsia. All these factors indicate that 
obesity may cause both cardiovascular conditions and preeclampsia, which is why the current study population has a high prevalence.

In this study, the mean age of the patients was also found to be significantly different ( $p$ $<0.001$ ) between control and preeclamptic group (Table I) demonstrating higher rates of young females in the control group with most elders were in the preeclamptic groups. This indicates an increasing risk of having preeclampsia as age advances, which was presented by many authors in their reviews [22]. Kumar et al also found maximum cases to be between 21-30 years of age, which further supports the present findings [23]. This is due to the increasing incidence of hypertension among older females along other medical illnesses which are risk factors to preeclampsia.

Additionally, the mean gestational age of patients was also observed in this study between the two groups. Similar results were reported by Luo Dong between control and preeclamptic patients [24]. However, study performed by Amit Gupta and Priyadarshini and colleagues found almost similar mean gestational ages with no significant difference between the patients and control. Differences in their case might be due to the inclusion of females with third trimester only $[25,26]$.

Our study revealed that majority of preeclamptic females $(n=65 ; 43.3 \%)$ belong to lower, while most of the control patients $(n=35 ; 23.3 \%)$ lie in upper socioeconomic status with highly significant differences (Table II). Females with low socioeconomic status tend to have less access to medical care which causes more severe pregnancy outcomes especially due to the lack of prenatal checkups. Our results were in agreement with the study performed by Haelterman et al., [27] who found an odds ratio of 2.3 (95\% CI: 1.2 - 4.4). However, the criteria of assessing socioeconomic status was quite different than ours (based on living facilities), that can be one of the reason of having low magnitude of effect in our study.

On the other hand, some researchers failed to find a link between socioeconomic status and preeclampsia [28, $29 \& 19]$. Differences in exposure or case definition might have contributed to these results. For example, Lawlor et al. preferred including the paternal occupation as a factor in the maternal socioeconomic status, thereby influencing the result significantly. Parazzini and Savitz et al altered their participants criteria in which women with pregnancy induced hypertension without proteinuria were included with preeclampsia. This caused discrepancies in the results due to having a more diverse group.

\section{STUDY LIMITATION:}

Patients were only recruited from one Province. Moreover, the documented pre-pregnancy weight was taken verbally at the initial antenatal care visit which may provide some inaccuracies.

\section{CONCLUSION:}

Based on the results, it's conclusive that having poor living status is the major risk factor for developing preeclampsia. The PreBMI, weight, age, blood pressure, platelet count and gestational age of the patients were proven to have a contribution to this condition. Further research is required to disengage the pathway leading socioeconomic status to preeclampsia.

\section{Ethics Approval and Consent to Participate}

Not applicable.

\section{Human and Animal Rights}


No animals were used in this study. The study on humans was conducted in accordance with the ethical rules of the Helsinki Declaration and Good Clinical Practice.

\section{Consent for Publication}

Not applicable.

\section{Availability of Data and Materials}

None.

\section{Funding}

None.

\section{Conflict of Interest}

The authors declare no conflict of interest, financial or otherwise.

\section{Acknowledgements}

None.

\section{REFERENCES:}

1. Ghulmiyyah, L., Sibai, B. aternal mortality from preeclampsia/eclampsia. Seminars Perinatol, 2011; 36 (1): 56-59.

2. Firoz, T, Sanghvi, H, Merialdi, M. Pre-eclampsia in low- and middle-income countries. Best Pract Res Clin Obstet Gynaecol, 2011; 25 (4): 537-548.

3. American College of Obstetricians and Gynecologists, Task Force on Hypertension in Pregnancy. Hypertension in pregnancy. Report of the American College of Obstetricians and Gynecologists' Task Force on Hypertension in Pregnancy. Obstet Gynecol. 2013; 122: 1122-31.

4. Hofmeyr, R., Matjilab, M., Dyer, R. Obstetric and Anaesthesia Management. Best Practice \& Research Clinical Anaesthesiology. 2016; 31(1): 125-13.

5. Tranquilli, A. L., Dekker, G., Magee, L. (2014). The classification, diagnosis and management of the hypertensive disorders of pregnancy: a revised statement from the ISSHP. Pregnancy Hypertens.2014; 4(2): 97-104.

6. Ahmed A, Rezai H, Broadway-Stringer S. Evidence-Based Revised View of the Pathophysiology of Preeclampsia. Adv Exp Med Biol. 2017; 956:355-374. doi: 10.1007/5584_2016_168. PMID: 27873232.

7. Khalil, G., Hameed, A. Preeclampsia: Pathophysiology and the Maternal-Fetal Risk. J Hypertens Manag.2017; 3; 024-30. doi.org/10.23937/2474-3690/1510024

8. Sava, R. I., Keith, L., Pepine, C. J. Hypertension in pregnancy: Taking cues from pathophysiology for clinical practice. Clinical Cardiology. 2018; 41: 220-227.

9. Gathiram, P. and Moodley, J. Pre-eclampsia: its pathogenesis and pathophysiolgy. Cardiovasc J Afr.2016; 27(2): 71-78.

10. Alasztics, B, Kukor, Z, Panczel, Z, Valent, S. The pathophysiology of preeclampsia in view of the two-stage model. Orv Hetil 2012; 153: 1167-1176.

11. Cox, B. Bioinformatic approach to the genetics of preeclampsia. Obstet Gynecol, . 2014:124, 633.

12. Easter, S.R., Cantonwine, D.E., Zera, C.A., Lim, K.H., Parry, S.I. Urinary tract infection during pregnancy, angiogenic factor profiles, and risk of preeclampsia. Am J Obstet Gynecol. 2017; 214: e1-e7.

13. Pare, E., Parry, S., McElrath, T. F., Pucci, D., Newton, A. Clinical risk factors for preeclampsia in the 21st century. Obstet Gynecol. 2014; 124: 763-770.

14. (Abalos et al., 2013).

15. Khidri, F. F., Waryah, Y. M., Ali, F. K. MTHFR and F5 genetic variations have association with preeclampsia in Pakistani patients: a case control study. BMC Med Genet 20.2019; 163-168. 


\section{Biosight 2021; 02(02): 50-57}

16. Omani-Samani, R., Ranjbaran, M., Amini, P., Esmailzadeh, A., Sepidarkish, M., Almasi-Hashiani, A. Adverse maternal and neonatal outcomes in women with preeclampsia in Iran, The Journal of Maternal-Fetal \& Neonatal Medicine.2019; 32(2): 212-216.

17. Muniyandi, M., Ramachandran, R., Gopi, P. G., Chandrasekaran, V., Subramani, R., Sadacharam, K., Kumaran, P., Santha, T., Wares, F., Narayanan, P.R. (2007). The prevalence of tuberculosis in different economic strata: a community survey from South India. Int J Tuberc Lung Dis. 2007; 11(9):1042-5.

18. Mrema, D., Lie, R.T., Mahande, M.J., Daltve, A.K. (2018). The association between pre pregnancy body mass index and risk of preeclampsia: a registry based study from Tanzania BMC. Pregnancy Childbirth. 2018; 18: 56-61.

19. Savitri, A. I., Zuithoff P., Browne J. L., Amelia D., Baharuddin M., Grobbee D. E. and Uiterwaal C. S. P. M. Does pre-pregnancy BMI determine blood pressure during pregnancy? A prospective cohort study.2016; 6(8): e011626.

20. Jeyabalan, A. Epidemiology of preeclampsia: impact of obesity. Nutrition Reviews; 2013; 71(1): S18-S25.

21. Mol, B. W., Roberts, C.T., Thangaratinam S. (2016). Preeclampsia. Lancet. PubMed. 2016; 387(10022):999-1011.

22. Henderson, J.T., Thompson, J.H., Burda, B.U., Cantor, A., Beil, T., Whitlock E.P. Screening for Preeclampsia: A Systematic Evidence Review for the U.S. Preventive Services Task Force. Agency for Healthcare Research and Quality. 2017; Report No: 14-05211-EF-1

23. Kumar, P. L., Nirmala, T., Vani, B. R., Srinivasa, M. V., Geetha, R. L. Study of coagulation profile in pregnancy induced hypertension (PIH). Indian J Pathol Oncol. 2015; 2(1): 1-6.

24. Dong, L., Yanyan, Z., Yi, B., Xijing, L., Yunhui, G., Bin, Z., Lin, Z., Linli, L., Rong, Z. Prostasin gene polymorphism at rs12597511 is associated with severe preeclampsia in Chinese Han women. Chinese medical journal.2014; 127: 2048-52. 10.3760/cma.j.issn.0366-6999.20133337.

25. Gupta, A., Bindu, S. G., Mishra, K. B., Dubey, I., Gupta, A. et al. A comparison of platelet count in severe preeclampsia, mild preeclampsia and normal pregnancy. International Journal of Research in Medical Sciences. 2018; 6(2): 671-676.

26. Priyadarshini, G. P., Mohanty, R. R. Assessment of coagulation profile and its correlation with severity of preeclampsia in women of odisha-a comparative cross-sectional study. Inter J Basic Applied Physiol, 2014; 3(1): 234-240

27. Haelterman E, Qvist R, Barlow P, Alexander S. Social deprivation and poor access to care as risk factors for severe preeclampsia. Eur J Obstet Gynecol Reprod Biol 2003; 111: 25-32.

28. Lawlor DA, Morton SM, Nitsch D, Leon DA. Association between childhood and adulthood socioeconomic position and pregnancy induced hypertension: results from the Aberdeen children of the 1950s cohort study. J Epidemiol Community Health 2005; 59:49-55.

29. Parazzini F, Bortolus R, Chatenoud L, Restelli S, Ricci E, Marozio L, Benedetto C. Risk factors for pregnancy-induced hypertension in women at high risk for the condition. Italian study of aspirin in pregnancy group. Epidemiology 1996; 7:306-308. 